\title{
Feeding of whole cottonseed on performance, carcass characteristics and intestinal morphology of Zandi lambs
}

\author{
M. Absalan ${ }^{1}$, A. Afzalzade ${ }^{1}$, M. Mirzaee ${ }^{2}$, S.D. Sharifi ${ }^{1}$, M. Khorvash ${ }^{2}$ \\ \& M. Kazemi-Benchenari ${ }^{3 \#}$ \\ ${ }^{1}$ Department of Animal Science, Abureyhan College of Agriculture, Tehran University, Tehran, Iran \\ ${ }^{2}$ Centre of Excellence in the Animal Science Department, Isfahan University of Technology, Isfahan, Iran \\ ${ }^{3}$ Department of Animal Science, Arak University, Arak, Iran
}

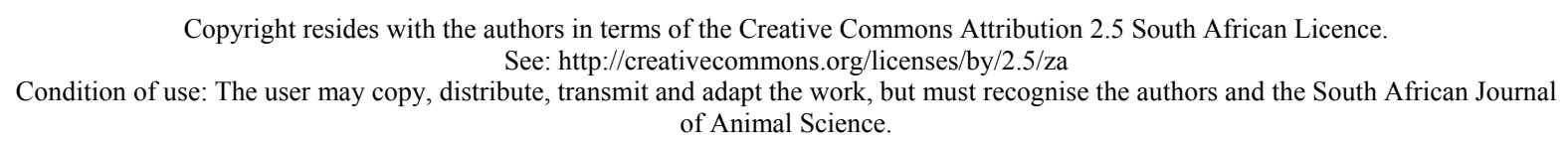

\section{tcartsbA}

The present study was conducted to determine the effect of including different levels of whole cottonseed (WCS) in the finishing diet of lambs on their dry matter intake (DMI), live weight gain, feed conversion ratio (FCR, $\mathrm{kg}$ feed/kg gain), carcass characteristics and small intestinal morphology. Twenty Zandi male lambs $(29.8 \pm 1.6 \mathrm{~kg}$ body weight $)$ were assigned to one of four diets in a completely randomized experimental design. The experimental diets contained $0 \%, 4 \%, 8 \%$ and $16 \%$ WCS on a dry matter (DM) basis. The diets were prepared as total mixed rations and fed to the lambs ad libitum. The lambs were slaughtered on day 90 and carcass data was collected. The DMI and average daily gain (ADG) were significantly greater for lambs fed the $8 \%$ WCS diet compared with the other treatments. The FCR was significantly lower in the diets containing WCS compared to the control, viz. 6.11, 5.6, 5.46 and 5.68, for treatments $0,4,8$ and $16 \%$ of WCS, respectively. However, the positive effects of including $8 \%$ cottonseed in the diet were significant in hot carcass weight, dressing percentage, liver, fat tail, intestinal fat and spleen compared with the control group. Furthermore, villous morphology and depth of crypt gland were affected by both diet and sampling site. No negative effects were observed in the organs and carcasses of the lambs that received different diets. The results indicate that the inclusion of $8 \%$ WCS in lamb diets could have a positive effect on most of the traits, but increasing the WCS inclusion up to $16 \%$ in the diet may have negative effects on lamb performance.

Keywords: Growth, finishing diet, carcass, sheep, gossypol

${ }^{\#}$ Corresponding author: m-kazemibonchenari@araku.ac.ir

\section{Introduction}

Whole cottonseed (WCS), a by-product of the cotton industry, has been used as a supplemental feedstuff in ruminant nutrition for over 100 years. It is unprocessed and contains a high level of crude protein (CP) with a high digestible energy content, making it a very useful by-product (Poore \& Rogers, 1995). Due to its high content of fat and protein, it can be defined as a concentrate. Furthermore, regarding effectiveness in the rumen, it has properties similar to forage fibre sources (Arieli, 1998). Increasing demands for energy and protein sources by ruminants have increased the importance of WCS as an energy and protein supplying ingredient. Due to the high energy, oil and protein contents, WCS is a popular feedstuff for ruminants and it has been accepted as an alternative to cereal grain in many rations (Kandylis et al., 1998).

However, WCS contains gossypol, a polyphenolic yellow pigment that may have detrimental effects on male reproduction (Randel et al., 1992). Moreover, the high content of fat and toxicity of gossypol had damaging effects on microbial activity in the rumen which is a limitation when including it in the diets of high-yielding dairy cattle (Arieli, 1998). 
Considering the low heat increment in the metabolism of WCS, this product seems to be desirable as a dietary supplement to animals kept under high environmental temperatures. In addition, WCS may promote growth and stimulate the functional development of the rumen (Anderson et al., 1982). Although WCS has been used extensively in cattle feeding systems (Poore \& Rogers, 1995; Arieli, 1998), it has not been fully investigated as a diet ingredient for small ruminants, especially for meat and dairy sheep. The purpose of this study was to evaluate the effects of different levels of WCS on dry matter intake (DMI), average daily gain (ADG), feed conversion ratio (FCR), carcass characteristics and intestinal morphology of Zandi fattening male lambs.

\section{Materials and Methods}

The experiment was conducted at the Research Station of Abureyhan, College of Agriculture University of Tehran, Iran. Twenty Zandi male lambs with an average age of 160 ( \pm 5 days) and weighing $29.8( \pm 1.6 \mathrm{~kg})$, were randomly allocated to 20 individual pens $(1 \times 1.4 \mathrm{~m})$. The experimental animals were assigned to one of the four treatments in a completely randomized design (five lambs per treatment).

The treatments were $0 \%, 4 \%, 8 \%$ and $16 \%$ WCS (based on DM) in the diets (Table 1). All diets were isonitrogenous and isoenergetic and contained $135 \mathrm{~g} \mathrm{CP} / \mathrm{kg} \mathrm{DM}$, thus meeting the requirements for finishing male lambs (NRC, 1985). The experiment lasted 90 days. The lambs were fed twice daily at 08:00 and 16:00. A total mixed ration diet (TMR) was offered to the lambs ad libitum, with free access to fresh water and a mineral lick. Orts were collected and weighed once a day before morning feeding, and the level of feeding was adjusted daily to yield orts at about $10 \%$ of intake. The animals were given a 15 -day adaptation period. During the adaptation phase all the animals were dewormed and sprayed against internal and external parasites. They were also vaccinated against pasteurelosis and anthrax. The lambs were weighed at weekly intervals before morning feeding. The FCR was calculated as daily DM intake divided by daily body weight gain (BWG).

Table 1 Ingredient and chemical composition of the four experimental diets (DM basis)

\begin{tabular}{lrrrr}
\hline \multirow{2}{*}{ Item } & \multicolumn{3}{c}{ \% Whole cottonseed in diet } \\
\cline { 2 - 5 } & 0 & 4 & 8 & 16 \\
\hline Ingredient (\% of DM) & & & 8 & 16 \\
Whole cottonseed (WCS) & 60 & 58 & 55 & 51 \\
Barley grain & 7 & 5 & 4 & 1 \\
Cottonseed meal & 15 & 15 & 15 & 15 \\
Lucerne hay & 18 & 18 & 18 & 17 \\
Barley straw & & & \\
Chemical composition & 11.1 & 11.2 & 11.3 & 11.5 \\
ME (MJ/kg DM) & 132 & 130 & 136 & 137 \\
Crude protein (g/kg) & 20.1 & 27.0 & 33.9 & 47.8 \\
Ether extract (g/kg) & 353 & 363 & 373 & 387 \\
Neutral detergent fibre (NDF) $(\mathrm{g} / \mathrm{kg})$ & 213 & 223 & 234 & 251 \\
Acid detergent fibre (ADF) $(\mathrm{g} / \mathrm{kg})$ & 4.8 & 4.9 & 3.8 & 4.2 \\
Calcium $(\mathrm{g} / \mathrm{kg})$ & 3.4 & 3.1 & 3.3 & 3.0 \\
Phosphorus (g/kg) & 171 & 192 & 184 & 165 \\
Iron (mg/kg) & & & & \\
\hline
\end{tabular}

ME - metabolizable energy, calculated according to NRC (1985) from diet component.

Diet samples were analyzed for crude protein (CP) (method 988.05; AOAC, 1990), neutral detergent fibre (NDF) (using heat-stable $\alpha$-amylase; Van Soest et al., 1991), acid detergent fibre (ADF) (method 
973.18; AOAC, 1990), ether extract (method 920.39; AOAC, 1990), calcium (titration method) and phosphorous (UV 2100-VIS Spectrophotometer Shimadzu, Kyoto, Japan). Iron concentrations in the diets were measured using atomic absorption spectrophotometry (Model 5000, Perkin Elmer, USA). At the end of the experiment all lambs were transported to a slaughterhouse, where they were weighed before being slaughtered to evaluate carcass characteristics. The lambs were prepared by trained personnel using standard slaughtering procedures (Abdullah et al., 1998) after being fasted for $c a .12 \mathrm{~h}$ with free access to fresh water. After slaughtering, the organs were removed according to normal dressing procedures. All edible carcass components (heart, head, liver, fat tail, kidneys and intestinal fat) and non-edible carcass components (skin with wool, testes, lungs and trachea, legs and spleen) were weighed immediately. The rumen and small intestine were cleaned and washed under cold running water before being weighed. Post-slaughter empty body weights were recorded. Hot carcass weight was computed by excluding edible and non-edible offals. The dressing percent was calculated as a proportion of the hot carcass weight after slaughter as well as the empty body weight (BW).

Sections of the small intestines were collected, i.e. the duodenum at $10 \mathrm{~cm}$ from the pyloric sphincter, the jejunum at $10 \mathrm{~cm}$ distal to the ligament of trite, and the ileum at $10 \mathrm{~cm}$ proximal to the ileocaecal junction; and also cleaned from digesta. These samples were placed in a formaldehyde and glutaraldehyde mixing fluid $(50 \mathrm{~mL} 0.2 \mathrm{M}, \mathrm{pH}=7.4$, sodium phosphate buffer, $10 \mathrm{~mL} 25 \%$ glutaraldehyde, $20 \mathrm{~mL} 10 \%$ formaldehyde polymer and $20 \mathrm{~mL}$ double-distilled water), 80\% (v/v) alcohol and Carnoy fluid (60 mL 100\% ethanol, $30 \mathrm{~mL}$ chloroform and $10 \mathrm{~mL}$ glacial acetic acid), respectively, and kept at $4{ }^{\circ} \mathrm{C}$ until further analysis (Gu \& Li., 2004). Cross-sections of the preserved intestinal samples were prepared using standard paraffin-embedding techniques. Samples were sectioned at $8 \mu \mathrm{m}$ thickness and stained with haematoxylin and eosin (Gu \& Li., 2004). Villous height (VH), villous width (VW) and crypt depth (CD) were measured on the stained sections under a microscope at $100 \times$ magnification and an ocular micrometer. A minimum of 20 straight, intact villi in each intestinal section were measured in triplicate. The VH parameter was measured from the tip of the villi to the villous crypt junction. The CD was defined as the depth of the invagination between adjacent villi and the VW was considered at the mid of the villous. The ratio of villous height : crypt depth $(\mathrm{VH} / \mathrm{CD})$ was determined as the ratio of $\mathrm{VH}$ to $\mathrm{CD}$.

The differences between experimental treatments were tested by the analysis of variance using the General Linear Model (GLM) procedures of SAS (2005) for a completely randomized design. The body weight was initially considered as a covariate factor in the statistical model. After analysis, the date of the initial body weight was removed due to it being insignificant. Statistical significance was considered at $P \leq 0.05$. The differences between treatments were tested using Duncan's multiple range tests.

\section{Results and Discussion}

The data on initial body weight, final live weight, live weight gain, ADG, DMI and FCR of the lambs is presented in Table 2 .

The DMI was significantly higher $(P<0.05)$ in lambs fed the $8 \%$ WCS diet compared with the other three treatments. These results differ from those of Luginbuhl et al. (2000) who reported that, using $24 \%$ of cottonseed in the diet of Boer goats decreased DMI compared with a control group. However, the increase in DMI, observed in the present study, is consistent with the results of Karalazos et al. (1992) who included 0, 17.5, 35.5 and 53.0\% WCS in a diet for rams. Coppock et al. (1987) stated that the DMI of dairy cattle did not change when up to $25 \%$ WCS was included in their diet. However, in some studies executed under hot environmental conditions (Coppock et al., 1985; Lanham et al., 1992), a decline in DMI did occur when WCS was fed. This drop in intake could be explained by the higher fibre content of diets high in WCS. In an experiment conducted in hot weather conditions where the fibre contents of the treatments were balanced, the supplementation of 20\% WCS did not reduce DMI (Belibasakis \& Tsirgogianni, 1995).

The increase in DMI due to the feeding of a higher percentage of WCS could be attributed to the regulatory effect of dietary energy intake. When the lambs were fed finishing rations, particle size of forage was small enough to avoid the regulation of feed intake by physical fill (Fimbers et al., 2002). The factors which can influence the DMI are divided into physiological, environmental and dietary factors. Of them, body composition, sex, physiological status and body size are categorized as physiological factors, and digestibility, dietary CP, amino acid situation, the imbalance of other ingredients in the diet, restriction of water, flavour and taste of feed and composition of diets are regarded as dietary factors. In the present study 
the concentration of fat, fibre, energy and perhaps CP degradability in the ration might have influenced the DMI of fattening lambs consuming WCS containing diets.

There were no significant differences between treatments in initial body weight (averaging $29.8 \pm 1.6$ $\mathrm{kg}$ ), final live weight and live weight gain of the experimental lambs (Table 2). However, different levels of inclusion of WCS resulted in different ADGs, with the highest ADG being in the $8 \%$ WCS treatment (Table 2). A gradual increase was recorded in the daily gain of the control group due to the $8 \%$ WCS treatment, and then a decrease in gain between the $8 \%$ and $16 \%$ WCS treatments.

The lower ADG in treatment $16 \%$ WCS could be related to both a higher gossypol content of the diet and a lower DMI compared with the other treatments. Kandylis et al. (1998) reported increased ADGs at levels of 10, 20 and 30\% WCS in the diets compared to a control diet. Bird et al. (1987) indicated that the addition of WCS to oaten chaff diets fed to sheep resulted in a lower growth rate. Luginbuhl et al. (2000) reported that the rate and efficiency of growth decreased at the higher levels of WCS inclusion in diets (up to $24 \%$ ). These studies suggest that the growth rate may be negatively affected by high dietary levels of WCS. The decline in the growth rate may be due to the depression in feed intake which was mentioned in previous studies, using high levels of WCS (Luginbuhl et al., 2000).

In this study the FCR of the lambs receiving $8 \%$ WCS in their diets was the best, i.e. the lowest, of all treatments $(P<0.05)$. In all treatments where WCS was included in the diets the FCR was lower than in the control diet. Similarly, Kandylis et al. (1998) found a reduction in FCR when animals were fed WCS at ration levels of 10, 20 and 30\%. Kuhlmann et al. (1991) reported that live weight gains increased and FCR decreased in heifers receiving $10-30 \%$ WCS in their diets.

Table 2 Performance of lambs fed four diets containing different levels of whole cottonseed for 90 days

\begin{tabular}{lccccr}
\hline \multirow{2}{*}{ Traits } & \multicolumn{4}{c}{ \% Whole cottonseed in diet } & \multirow{2}{*}{ SEM } \\
\cline { 2 - 5 } & 0 & 4 & 8 & 16 & 1.6 \\
\hline Initial body weight (kg) & 29.9 & 29.9 & 30.0 & 29.8 & 2.1 \\
Final live weight (kg) & 51.0 & 52.6 & 54.5 & 51.8 & 1.3 \\
Live weight gain & 21.1 & 22.7 & 24.5 & 22.0 & 8.13 \\
Average daily gain (g/day) & $234^{\mathrm{c}}$ & $252^{\mathrm{b}}$ & $272^{\mathrm{a}}$ & $244^{\mathrm{bc}}$ & 0.012 \\
Dry matter intake(DMI, kg/day) & $1.43^{\mathrm{b}}$ & $1.41^{\mathrm{b}}$ & $1.48^{\mathrm{a}}$ & $1.38^{\mathrm{c}}$ & 0.05 \\
FCR (kg DMI/kg gain) & $6.11^{\mathrm{a}}$ & $5.59^{\mathrm{b}}$ & $5.44^{\mathrm{c}}$ & $5.65^{\mathrm{b}}$ & \\
\hline
\end{tabular}

${ }^{a b c}$ Means with different superscripts in the same row are significantly different $(P<0.05)$.

$\mathrm{SEM}=$ standard error of mean; FCR - feed conversion ratio.

The effects of the different levels of WCS on hot carcass weight, dressing percentage and the weight of various internal and external organs of the lambs are presented in Table 3.

The inclusion of $8 \%$ WCS in the diets increased the hot carcass weight and dressing percentage compared with the other treatments $(P<0.05)$. This is consistent with the results obtained by Kandylis et al. (1998). Diets and nutrient contents may also affect carcass characteristics and meat quality. Kandylis et al. (1998) indicated that growing lambs fed WCS had a higher live weight, increased hot carcass weight and dressing percentage in comparison with a control diet. The low dressing percentage (slaughter-weight basis) in the control group could be due to a high gut fill which would reduce the dressing percentage. The dressing percentage of the Zandi breed, based on body weight at slaughter, has been recorded as 51.6 (Kyanzad, 2001; Kashan et al., 2005). The average slaughter weight and hot carcass weight of lambs fed the diet containing $8 \%$ WCS were heavier than in the other treatments, similar to final live weight.

In the present study no significant differences were recorded for most of the carcass performance data, and the weights of the internal and external organs (Table 3). The weights of the empty small intestines, empty rumen, lungs and trachea, heart, head, kidney, skin with wool, testes and legs were not affected by 
dietary WCS levels. However, the weights of intestinal fat, fat tail, liver and spleen were significantly influenced by the level of dietary WCS; probably because of a higher dietary fat content.

Butler-Hogg \& Johnsson (1986) recorded $260 \mathrm{~g}$ intestinal fat for lambs slaughtered at $32 \mathrm{~kg}$ live weight. However, in the present study we obtained values ranging from 489 to $597 \mathrm{~g}$ that is highly related to the greater weight of the lambs. It has also been reported that with increasing amounts of WCS in the diet, the site of fat depots tends to change (Huerta-Leidenz et al., 1991). Fat-tailed sheep breeds that are found in the most parts of Asia, are probably more tolerant to protracted feed shortages, compared to European breeds. Some researchers showed that the changes in weight of some organs, especially the small intestine, large intestine, heart, lung, liver and kidney, are related to metabolic activity which is affected by breed, diet, husbandry system and slaughtering age (Pearson \& Dutson, 1991). In order to yield a high carcass percentage, the lamb must have a light pelt, the well finished and heavily muscled, and free from paunchiness. Due to the higher value of the offal of sheep compared with other species, especially the high value of the pelt, a high dressing percentage in sheep is not as important economically as in cattle or pigs. Wool yield is not usually an important item in slaughter and the dressing return, and dressing percentage lowered by a heavier wool yield may actually mean a greater total return. For this reason, the fleece characteristics should be an important production component in the production of mutton or lamb of high quality (Enseminger, 2002).

Morphology results of the duodenum, jejunum and ileum are presented in Table 4. The level of WCS in the ration had significant effects on villi height, villous width and villous/crypt ratio in the duodenum $(P<0.05)$. The greatest values for villi height and villous/crypt ratio were observed in the $8 \%$ dietary WCS

Table 3 Effect of whole cottonseed on carcass measurements of lambs slaughtered after 90 days

\begin{tabular}{|c|c|c|c|c|c|}
\hline \multirow{2}{*}{ Item } & \multicolumn{4}{|c|}{$\%$ Whole cottonseed in diet } & \multirow{2}{*}{ SEM } \\
\hline & 0 & 4 & 8 & 16 & \\
\hline Slaughter live weight (kg) & 51.0 & 52.6 & 54.5 & 51.8 & 2.1 \\
\hline Hot carcass weight $(\mathrm{kg})$ & $25.8^{\mathrm{b}}$ & $26.9^{\mathrm{ab}}$ & $29.6^{\mathrm{a}}$ & $26.4^{\mathrm{b}}$ & 0.63 \\
\hline Dressing percentage, hot carcass & $50.6^{\mathrm{b}}$ & $51.2^{\mathrm{b}}$ & $53.2^{\mathrm{a}}$ & $50.9^{\mathrm{b}}$ & 0.38 \\
\hline \multicolumn{6}{|l|}{ Edible carcass (g) } \\
\hline Heart & 227 & 245 & 252 & 237 & 6.2 \\
\hline Head & 2058 & 2203 & 2203 & 2115 & 38.8 \\
\hline Liver & $827^{\mathrm{b}}$ & $830^{\mathrm{b}}$ & $897^{\mathrm{b}}$ & $1051^{\mathrm{a}}$ & 28.7 \\
\hline Kidney & 231 & 317 & 297 & 299 & 16.4 \\
\hline Empty rumen & 1220 & 1371 & 1282 & 1343 & 37.9 \\
\hline Empty small intestine & 559 & 551 & 592 & 532 & 13.4 \\
\hline Fat tail & $3582^{\mathrm{b}}$ & $3710^{\mathrm{ab}}$ & $3734^{\mathrm{ab}}$ & $4511^{\mathrm{a}}$ & 165.8 \\
\hline Testes & 436 & 488 & 457 & 411 & 18.1 \\
\hline Intestinal fat & $489^{\mathrm{b}}$ & $512^{\mathrm{b}}$ & $583^{\mathrm{a}}$ & $597^{\mathrm{a}}$ & 21.8 \\
\hline \multicolumn{6}{|l|}{ Non-edible carcass offal (g) } \\
\hline Skin with wool & 5990 & 6680 & 6900 & 6350 & 162.4 \\
\hline Lungs and trachea & 551 & 641 & 593 & 588 & 20.3 \\
\hline Legs & 926 & 931 & 1025 & 956 & 19.2 \\
\hline Spleen & $97^{\mathrm{b}}$ & $121^{\mathrm{a}}$ & $127^{\mathrm{a}}$ & $130^{\mathrm{a}}$ & 4.6 \\
\hline
\end{tabular}

${ }^{a b c}$ Means with different superscripts in the same row are significantly different $(P<0.05)$.

$\mathrm{SEM}=$ Standard error of means.

among treatments. However, the villous width was larger in the control treatment compared with the other treatments. In the jejunum, different levels of WCS in the ration had significant effects on villi height and the 
villous height : crypt depth ratio. Similar to the parameters observed in the duodenum, the villi height and $\mathrm{VH} / \mathrm{CD}$ were the highest in the $8 \%$ WCS treatment in the present study. As it has shown in Table 4, all morphological parameters in the ileum were affected by diet $(P<0.05)$.

Table 4 Effect of feeding whole cottonseed on morphology of different segments in the small intestines

\begin{tabular}{lrrrrr}
\hline Site & \multicolumn{4}{c}{$\%$ Whole cottonseed in diet } & SEM \\
\cline { 2 - 4 } & 0 & 4 & 8 & 16 & \\
\cline { 2 - 4 } Duodenum & & & & \\
$\quad$ Villous height $(\mu \mathrm{m})$ & $290^{\mathrm{b}}$ & $303^{\mathrm{ab}}$ & $346^{\mathrm{a}}$ & $344^{\mathrm{a}}$ & 9.7 \\
Villous width $(\mu \mathrm{m})$ & $300^{\mathrm{a}}$ & $297^{\mathrm{ab}}$ & $297^{\mathrm{ab}}$ & $2633^{\mathrm{b}}$ & 6.2 \\
Crypt depth $(\mu \mathrm{m})$ & 273 & 240 & 263 & 243 & 7.2 \\
VH/CD & $1.06^{\mathrm{b}}$ & $1.27^{7^{\mathrm{ab}}}$ & $1.42^{\mathrm{a}}$ & $1.31^{\mathrm{ab}}$ & 0.05 \\
Jejunum & & & & \\
Villous height $(\mu \mathrm{m})$ & $237^{\mathrm{c}}$ & $280^{\mathrm{b}}$ & $327^{\mathrm{a}}$ & $303^{\mathrm{ab}}$ & 11.3 \\
Villous width $(\mu \mathrm{m})$ & 257 & 280 & 283 & 253 & 7.4 \\
Crypt depth $(\mu \mathrm{m})$ & 210 & 247 & 250 & 247 & 7.4 \\
VH/CD & $1.12^{\mathrm{b}}$ & $1.13^{\mathrm{ab}}$ & $1.32^{\mathrm{a}}$ & $1.23^{\mathrm{ab}}$ & 0.03 \\
Ileum & & & & \\
Villous height $(\mu \mathrm{m})$ & $243^{\mathrm{c}}$ & $283^{\mathrm{b}}$ & $327^{\mathrm{a}}$ & $290^{\mathrm{b}}$ & 10.2 \\
Villous width $(\mu \mathrm{m})$ & $253^{\mathrm{b}}$ & $273^{\mathrm{ab}}$ & $300^{\mathrm{a}}$ & $280^{\mathrm{ab}}$ & 7.2 \\
Crypt depth $(\mu \mathrm{m})$ & $217^{\mathrm{b}}$ & $237^{\mathrm{ab}}$ & $257^{\mathrm{a}}$ & $237^{\mathrm{ab}}$ & 5.3 \\
VH/CD & $1.12^{\mathrm{b}}$ & $1.19^{\mathrm{ab}}$ & $1.27^{\mathrm{a}}$ & $1.22^{\mathrm{ab}}$ & 0.02 \\
\hline
\end{tabular}

${ }^{\mathrm{abc}}$ Means with different superscripts in the same row are significantly different $(P<0.05)$.

$\mathrm{SEM}=$ standard error of mean.

$\mathrm{VH} / \mathrm{CD}=$ villous height $:$ crypt depth.

The villi of the small intestine changes with both age and weaning time, from a long and fine fingerlike shape to a short and thick tongue-like shape (Kenworthy, 1976; Cera et al., 1988). A high sensitivity to antigens in the diet may be responsible for morphological changes such as villous atrophy and crypt hypertrophy (Kenworthy, 1976). Diets containing high CP levels, especially those with high levels of plant protein that may contain strong antigens, may greatly affect villous morphology (Li et al., 1991). In this experiment the villous height was significantly affected by different levels of WCS. Villous height : crypt depth ratio in the duodenum, villous height and $\mathrm{VH} / \mathrm{CD}$ in the jejunum and villous height, villous width, crypt depth and $\mathrm{VH} / \mathrm{CD}$ in the ileum were also affected.

As the dietary WCS level increased, all morphological parameters of the small intestines were affected significantly. In the entire length of the small intestines of the experimental lambs, villous heights and villous width as well as crypt depth were higher in lambs that were fed WCS compared to the control group. The lambs that were fed the control diet in this study had the lowest $\mathrm{VH} / \mathrm{CD}$ which probably relates to the lower digestive capacity of the small intestines in these animals. Villous height and villous width as well as villous height : crypt depth ratios were longer in the duodenum. These results are in agreement with that of Sharifi et al. (2007) who studied the small intestine morphology in chickens. Studying intestinal morphology traits when the level of CP in piglet diets was increased, Gu \& Li (2004) showed that the villous height in the duodenum was longer than in other segments, in agreement with the present results. We assumed that gossypol in WCS may affect the villous morphology in the small intestines. In another study on broilers, Gabriel et al. (2007) reported that villous height, crypt depth and villous height : crypt depth ratios were affected by wholewheat grain and the highest villous height, crypt depth and villous height : crypt depth ratios were observed in the duodenum and the lowest in the jejunum. A similar result in piglets was reported 
by Hedemann et al. (2007). Changes in the development of the enterocytes and in the structure of villi determine the digestive and absorptive capacity of the small intestines. Hampson (1986) reported that by measuring the villous height and studying villous shape one can estimate the number of entrocyte in the villous. In other words, if the villi are longer and flatter, the entrocyte surface will be longer and consequently, absorption ability will be higher. Villous height, crypt depth and the ratio of VH/CD reflect intestinal health (Wang et al., 2008). Sharifi et al. (2007) reported that a reduction in villous height caused by soluble non-starch polysaccharide can reduce nutrients' digestibility. An increase in VH/CD in the intestinal structure is related to better digestion and absorption of nutrients due to the provision of the required nutrients (Gabriel et al., 2008). Wang et al. (2008) reported that greater villous height, villous width, crypt depth and villous height : crypt ratios were observed in the duodenum of goats receiving WCS. The positive effect of WCS on villous height and villous height: crypt depth ratio can improve the nutrient uptake from the intestines which could result in improved growth performance in comparison with control diets. The greater duodenal villous height : crypt depth ratio in lambs fed WCS may reflect the higher level of energy absorbed from the duodenum, which could be the result of the volatile fatty acids formed through the degradation of WCS. The increased villous height : crypt depth ratio showed an intestinal structure more conducive to digestion, with improved absorptive and hydrolysis potential, than the required nutrients for intestinal maintenance. Thus, with the inclusion of WCS in the diet, the intestinal structure of the duodenum was more favourable for the animal and may contribute to the improved FCR.

Moreover, pervious studies on the interaction of iron supplementation with cottonseed feeding indicated that iron could ameliorate the negative effects of gossypol in the ruminant (Barraza et al., 1991; Santos et al., 2005; McCaughey et al., 2005). Barraza et al. (1991) suggested that iron could bind with gossypol and reduce gossypol availability in the digestive tract. Santos et al. (2005) also reported that iron supplementation in the form of iron sulphate decreased plasma gossypol in Holstein steers. However, in our study the relatively low concentration of iron could probably not affect the gossypol absorption in the small intestines and the gossypol concentration in the plasma of fattening lambs.

\section{Conclusion}

The inclusion of different levels of WCS in the finishing diets of lambs was investigated in the present study. The results indicated that DMI, FCR, carcass weight, fat tail weight, liver and spleen weights were affected positively by the inclusion of WCS in the diets. Furthermore, WCS feeding affected the morphology of villous and crypt in the small intestines. The results suggested that an inclusion of $8 \%$ WCS in the diet was the most effective in improving most of the traits, and that a $16 \%$ inclusion of WCS affected some of the performance traits negatively.

\section{Acknowledgements}

The authors wish to acknowledge the financial support provided by the University of Tehran, Iran.

\section{References}

Abdullah, A.Y., Purchas, R.W. \& Davies, A.S., 1998. Patterns of change with growth for muscularity and other composition characteristics of Southdown rams selected for high and low back depth. N. Z. J. Agric. Res. 41, 367-376.

Anderson, M.J., Khoyloo, M. \& Walters, J.L., 1982. Effect of feeding whole cottonseed on intake, body weight, and reticulorumen development of young Holstein calves. J. Dairy Sci. 65, 764-772.

AOAC, 1990. Official Methods of the Association of Official Analytical Chemists. 12th ed. AOAC, Washington. DC, USA. pp. 267-273.

Arieli, A., 1998. Whole cottonseed in dairy cattle feed: A review. Anim. Feed Sci. Technol. 72, 97-110.

Barraza, M.L., Coppock, C.E., Brooks, K.N., Wilks, D.L., Saunders, R.G. \& Latimer, G.W., 1991. Iron sulfate and feed pelleting to detoxify free gossypol in cottonseed diets for dairy cattle. J. Dairy Sci. 74, $3457-3467$.

Belibasakis, N.G. \& Tsirgogianni, D., 1995. Effect of whole cottonseed on milk yield, milk composition, and blood components of dairy cows in hot weather. Anim. Feed Sci. Technol. 52, 227-235.

Bird, S.H., Dicko, M. \& Farrell, D.J., 1987. Cottonseed supplement for sheep. Recent Adv. Anim. Nutr. 1987, 80-88. 
Butler-Hogg, B.W. \& Johnsson, I.D., 1986. Fat partitioning and tissue distribution in crossbred ewes following different growth paths. Anim. Prod. 42, 65-72.

Cera, K.R., Mahan, D.C., Cross, R.F., Reinhart, G.A. \& Whitmover, R.E., 1988. Effect of age, weaning and postweaning diet on small intestinal growth and jejunum morphology in young swine. J. Anim. Sci. $66,574-584$.

Coppock, C.E., West, J., Moya, J.R., Nave, D.H., LaBore, J.M., Thompson, K.G., Rowe Jr., L.D. \& Gates, C.E., 1985. Effects of amount of whole cottonseed on intake, digestibility, and physiological responses of dairy cows. J. Dairy Sci. 68, 2248-2258.

Coppock, C.E., Lanham, J.K. \& Horner, J.I., 1987. A review of the nutritive value and utilization of whole cottonseed, cottonseed meal and associated by-products by dairy cattle. Anim. Feed Sci. Technol. 18, 89-129.

Enseminger, M.E., 2002. Sheep and Goat Science, 6th ed. Interstate Publisher, Inc., Denville, Illinois. p. 510.

Fimbers, D.H., Hernandez, V.G., Picon, R.J.F., Kawas, J.R. \& Lu, C.D., 2002. Nutrient intake, digestibility, mastication and ruminal fermentation of lambs fed finishing ration with various forage levels. Small Rumin. Res. 43, 283-288.

Gabriel, I., Mallet, S., Leconte, M., Travel, A., Lalles, J.P., 2008. Effects of whole wheat feeding on the development of the digestive tract of broiler chickens. Anim. Feed Sci. Technol. 142, 144-162.

$\mathrm{Gu}, \mathrm{X} . \& \mathrm{Li}, \mathrm{D} ., 2004$. Effect of dietary crude protein level in villous morphology, immune status and histochemistry parameters of digestive tract in weaning piglets. Anim. Feed Sci. Technol. 114, 113-126.

Hampson, D.J., 1986. Alteration in piglet small intestinal structure at weaning. Res. Vet. Sci. 40, 39-40.

Hedemann, M.S., Knud, E. \& Bach, K., 2007. Resistant starch for weaning pigs - Effect on concentration of short chain fatty acids in digesta and intestinal morphology. Livest. Sci. 108, 175-177.

Huerta-Leidenz, N.O., Cross, H.R., Lunt, D.K., Pelton, L.S., Savell, J.W. \& Smith, S.B., 1991. Growth, carcass traits, and fatty acid profiles of adipose tissues from steers fed whole cottonseed. J. Anim. Sci. 69, 3665-3672.

Kandylis, K., Nikokyris, P.N. \& Deligiannis, K., 1998. Performance of growing-fattening lambs fed whole cotton seed. J. Sci. Food Agric. 78, 281-289.

Karalazos, A., Dotas, D. \& Bikos, J., 1992. A note on the apparent digestibility and nutritive value of whole cottonseed given to sheep. Anim. Prod. 55, 285-287.

Kashan, N.E.J., Manafi Azar, Gh., Afzalzadeh, A. \& Salehi, A., 2005. Growth performance and carcass quality of fattening lambs from fat-tailed and tailed sheep breeds. Small Rumin. Res. 60, 267-27.

Kenworthy, R., 1976. Observations on the effects of weaning in the young pig: clinical and histopathological studies of intestinal function and morphology. Res. Vet. Sci. 21, 69-75.

Kuhlmann, S.W., Calhoun, M.C., Huston, J.E., Baldwin, B.C., Engdahl Jr., B.S. \& Ueckert, D.N., 1991. Increased erythrocyte fragility in cattle, sheep and goats fed whole cottonseed. J. Anim. Sci. 69, 63-64.

Kyanzad, M.R., 2001. Crossbreeding of the three Iranian sheep breeds with emphasis on growth and carcass characteristics of the lambs. PhD thesis, University of Putra, Malaysia.

Lanham, J.K., Coppock, C.E., Brooks, K.N., Wilks, D.L. \& Horner, J.L., 1992. Effect of whole cottonseed or niacin or both on casein synthesis by lactating Holstein cows. J. Dairy Sci. 75, 184-192.

Li, D.F., Nelssen, J.L., Reddy, P.G., Blecha, F., Klemm, R. \& Goodband, R.D., 1991. Inter-relationship between hypersensitivity to soybean proteins and growth performance in early-weaned pigs. J. Anim. Sci. 69, 4062-4069.

Luginbuhl, J.M., Poore, M.H. \& Conrad, A.P., 2000. Effect of level of whole cottonseed on intake, digestibility and performance of growing male goats fed hay-based diets. J. Anim. Sci. 78, 1677-1683.

McCaughey, K.M., DePeters, E.J., Robinson, P.H., Santos, J.E.P., Pareas, J.W. \& Taylor, S.J., 2005. Impact of feeding whole Upland cottonseed, with or without cracked Pima cottonseed with increasing addition of iron sulfate, on productivity and plasma gossypol of lactating dairy cattle. Anim. Feed Sci. Technol. 122, 241-256.

NRC, 1985. Nutrient requirements of Sheep. 6th rev ed. National Academy Press, Washington, D.C.

Pearson, A.M. \& Dutson, T.R., 1991. Growth Regulation in Farm Animals: Advances in Meat Research. Published by Springer. $636 \mathrm{pp}$.

Poore, M.H. \& Rogers, G., 1995. Feeding whole cottonseed and other cotton by-products to beef cattle. Vet. Med. 90, 1077-1087. 
Randel, R.D., Chase Jr., C.C. \& Wyse, S.J., 1992. Effects of gossypol and cottonseed products on reproduction of mammals. J. Anim. Sci. 70, 1628-1638.

Santos, J.E.P., Mena, H., Huber, J.T. \& Tarazon, M., 2005. Effect of source of gossypol and iron supplementation on plasma gossypol concentrations and performance of growing Holstein steers. J.Dairy Sci. 88, 3563-3574.

SAS, 2005. Statistical Analysis Systems procedure guide (Version 9). SAS Institute Inc., N.C., USA. $1643 \mathrm{pp}$.

Sharifi, S.D., Shariatmadari, F., Yaghubfar, A. \& Tashfam, M., 2007. The study of different concentrations of soluble non-starch polysaccharide in rations on morphological traits of digestive tract and performance of broiler chickens. J. Vet. Res. 62, 115-120 (in Persian).

Van Soest, P.J., Robertson, J.B. \& Lewis, B.A., 1991. Methods for dietary fiber, neutral detergent fiber, and nonstarch polysaccharides in relation to animal nutrition. J. Dairy Sci. 74, 3583-3597.

Wang, Y.H., Xu, M., Wang, F.N., Yu, Z.P., Yao, J.H., Zan, L.S. \& Yang, F.X., 2008. Effect of dietary starch on rumen and small intestine morphology and digesta $\mathrm{pH}$ in goats. Livest. Sci. 122, 48-52. 